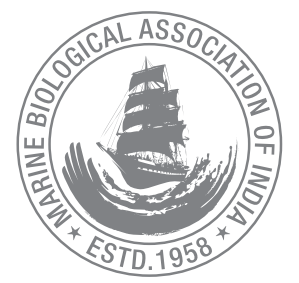

\title{
Diversity of zooplankton along the northern part of Vembanad lake, Kerala, India
}

\author{
Asha Ravi ${ }^{1,2 *}$, K. R. Aju', K. M. Sreekumar ${ }^{1}$ and Molly Varghese ${ }^{1}$ \\ 'ICAR-Central Marine Fisheries Research Institute, Kochi-682 018, Kerala, India. \\ ${ }^{2}$ Cochin University of Science and Technology, ,Kochi-682 022 Kerala, India. \\ *Correspondence e-mail: ashamply@gmail.com
}

Received: 17 Feb 2020 Accepted: 20 Nov 2020 Published: 25 Nov 2020

Original Article

\begin{abstract}
Zooplankton samples collected from six stations, along the KollamKottappuram waterway (National Waterway 3) on the northern part of Lake Vembanad on monthly intervals during October 2018 to September 2019 formed the basis of this study. The samples were analysed both qualitatively and quantitatively by adopting standard methods. 23 groups of zooplankton were recorded from the study area. Out of these, a maximum of 18 groups were recorded from station 1 (Cochin bar mouth) and a minimum of 9 groups from station 6 (Kottappuram). Overall average density of zooplankton in the study area was 3044 numbers per $100 \mathrm{~m}^{3}$. Station-wise studies indicated that the average zooplankton density was maximum (4882 per $100 \mathrm{~m}^{3}$ ) at station 2 (Kadamakudy) and minimum (1649 per $100 \mathrm{~m}^{3}$ ) at station 5 (Azhikode bar mouth). Among the different groups of zooplankton in the study area, a maximum of $79 \%$ was contributed by copepods, $14 \%$ by rotifers while the remaining groups contributed less than $2 \%$ each. Month-wise analysis indicated the maximum density during September and the minimum during January. Biodiversity analyses were carried out by Primer v. 6 software. From the cluster analysis and Bray-Curtis similarity matrix, July and August months showed the maximum similarity of species composition compared to all other months.
\end{abstract}

Keywords: Zooplankton, diversity, distribution, density, Cochin backwaters.

\section{Introduction}

Zooplankton are highly sensitive to changes in aquatic ecosystems and their distribution in polluted and non-polluted waters can provide information regarding the productivity and pollution of that area (Gajbhiye and Desai, 1981). They support the fishery resources of most of the aquatic ecosystems and these in turn will be influenced by various physical, chemical and biological factors. Being the secondary producers in the aquatic food web, they are of considerable importance as a food resource to larval as well as the adult stages of several marine, estuarine and freshwater organisms (Maya, 1991). In estuaries and backwaters, the zooplankton distribution varies considerably in space and time depending on the physical and chemical properties of water. Estuaries are among the most productive aquatic ecosystems where the interplay of fresh and coastal waters continuously changes the physical, chemical and biological properties of estuarine ecosystems. In an estuarine system, the changes in salinity level cause the decrease in species diversity and richness (Giesecke et al., 2017). 
Considerable works, both qualitative and quantitative, has been done in Indian coastal waters. Several studies related to the distribution of zooplankton in Indian estuaries have been done by Srinivasan and Santhanam (1991); Nandan and Azis (1994) and Qasim (2005). General composition of the zooplankton in Cochin backwaters was first published by George (1958). Seasonal changes of zooplankton in the Cochin backwaters has been studied by Nair and Tranter (1971) and Wellershaus (1974); fluctuation of zooplankton in Cochin estuary was studied by Maya (1991); diversity of zooplankton in selected centres adjoining Cochin backwater by Varghese and Krishnan (2009) and species diversity of rotifers at the southern part of Lake Vembanad by Cleetus et al. (2015). From these existing literature, it is clear that along the northern part of the lake, such studies are very scarce. Therefore, it is important to know the distributional pattern of zooplankton along the northern part of the Lake Vembanad which is under vigorous human activities.

\section{Material and methods}

Lake Vembanad is the longest lake in India, lying north-south across Southern Kerala parallel to the Arabian Sea on the west coast. It opens to the sea at two points; one in the south, at Kochi and the other at Azhikode in the north. It is the second largest Ramsar site in India covering an area of 2033.02 sq.

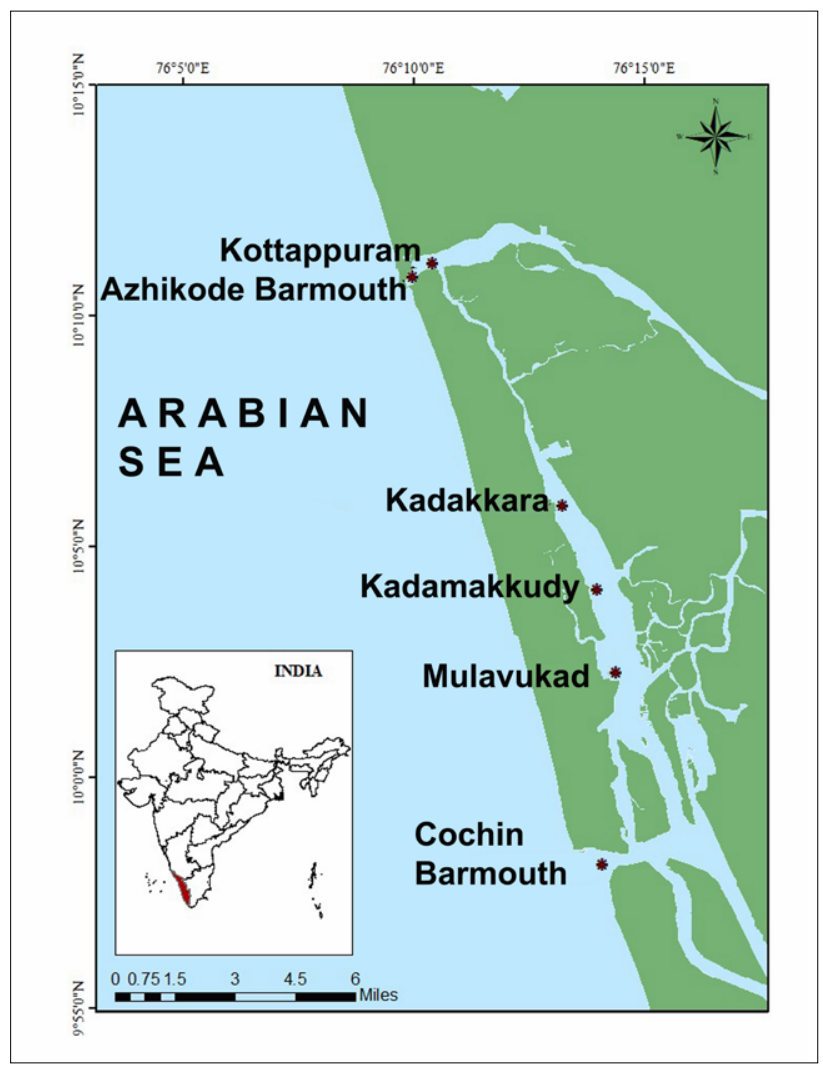

Fig.1. Map showing the sampling stations $\mathrm{km}$. The national waterway 3 or the West-coast canal is a $168 \mathrm{~km}$ stretch of inland navigational route located along the Vembanad backwaters. The selected study area is a part of this waterway from Kochi to Kottappuram (33Km). Six stations were selected starting from Cochin bar mouth (St:1), Mulavukad (St:2), Kadamakkudy (St:3), Kadakkara (St:4), Azhikode barmouth (St:5) and Kottappuram (St:6). The map showing the study area is given in Fig. 1. The quantity of fresh water entering the lake depends greatly on the discharge by River Periyar with its branches entering the lake at various locations. Depth of the lake varies across its entire stretch. Maximum depth of $15 \mathrm{~m}$ is recorded in the dredged channel at Cochin barmouth while at Azhikode barmouth it is around $10 \mathrm{~m}$. Between these two stations the depth varied from $0.5 \mathrm{~m}$ to $3 \mathrm{~m}$.

Zooplankton samples were collected by horizontally towing a conical plankton net having a mesh size of $45 \mu \mathrm{m}$ for 10 minutes. The collected samples were preserved in $4 \%$ formalin. The samples were observed under a compound microscope and different groups of zooplankton were identified and enumerated using standard taxonomic books such as those by Newell and Newell (1973), Battish (1992) and Phan et al. (2015).

Count of organisms per $100 \mathrm{~m}^{3}$ of water was calculated. Month wise data for a period of 1 year were grouped for this study from October, 2018 to September, 2019. For seasonal studies, October-January was treated as post-monsoon, Feb-May as premonsoon and June-September as monsoon. The zooplankton groups of all the six stations for individual months were clubbed and month-wise species diversity analysis for all groups were carried out. Diversity indices and Bray-Curtis similarity coefficients were calculated using the PRIMER software (Clarke and Gorley, 2006). Bray Curtis similarity coefficients were calculated for studying the species composition similarity. Similarity matrices were constructed using the Bray Curtis measure. The similarity is taken as $100 \%$ when the two samples are totally similar and as 0 when the samples are totally dissimilar. In cluster analysis, hierarchical agglomerative clustering the Bray Curtis similarity was used to construct the map, (Clarke and Warwick, 2001). All the univariate and multivariate analysis for the diversity profile were done using PRIMER (Plymouth Routines In Multivariate Ecological Research) version. 6 package developed by the Plymouth Marine Laboratory, UK (Clarke and Gorley, 2006).

\section{Results and discussion}

\section{Quantitative distribution}

Average density of zooplankton from the study area during the study period was 3044 numbers per $100 \mathrm{~m}^{3}$. Density of zooplankton was maximum at station $2\left(4882\right.$ per $\left.100 \mathrm{~m}^{3}\right)$ followed by station $1\left(4301\right.$ per $\left.100 \mathrm{~m}^{3}\right)$. But it was the least at station 
$5\left(1649\right.$ per $100 \mathrm{~m}^{3}$ ) (Fig. 2). Seasonal variation of zooplankton is given in Fig. 3. In the majority of stations, zooplankton density was higher during post-monsoon and pre-monsoon seasons except at stations $1 \& 2$ where it was highest during monsoon. From month wise analysis, maximum average density was observed in September (6773 per $\left.100 \mathrm{~m}^{3}\right)$ and minimum in January (267 per $100 \mathrm{~m}^{3}$ ). Higher density zooplankton especially copepods during this low salinity period was mainly due to the increased abundance of the low saline copepod Acartiella gravelyi (Pillai et al., 1973; Vineetha et al., 2015). Abundance of zooplankton during the pre-monsoon was reported earlier also by Madhu et al. (2007) in Cochin backwaters.

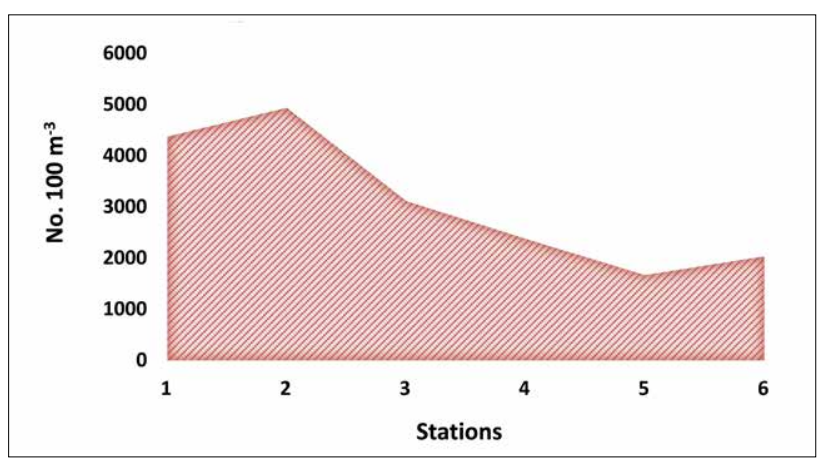

Fig. 2. Station wise distribution of zooplankton in the study area

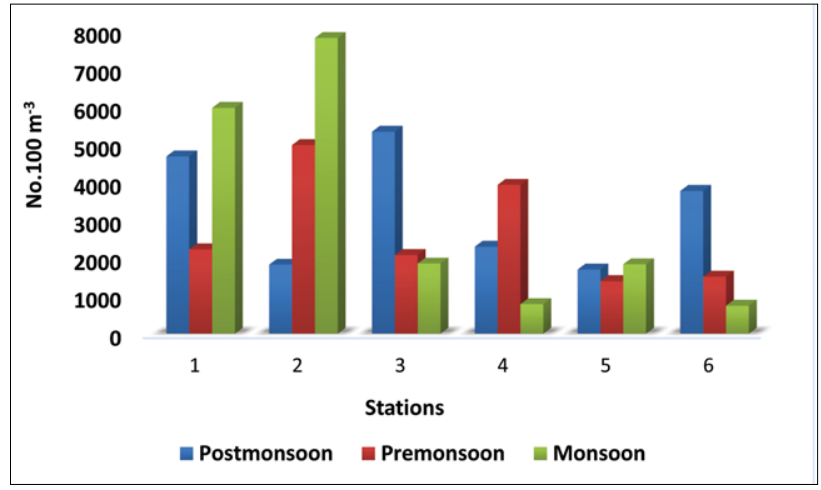

Fig. 3. Seasonal variations of zooplankton in the study area

\section{Qualitative distribution}

During the present study, 23 groups of zooplankton were recorded from the six stations. They were copepods, rotifers, foraminiferans, tintinnids, medusae, ephyra larvae, ctenophores, chaetognaths, polychaetes, trochophores, cladocerans, ostracods, Balanus nauplii, siphonophores, Lucifer spp., amphipods, tunicates, decapod larvae, crab zoea, bivalve veliger, gastropods, fish eggs and fish larvae. Distribution of zooplankton in different stations is given in Table 1. Salinity profile for the three seasons is given in Fig. 4 and the community structure of zooplankton in different stations is given in Fig. 5 .
Table 1. Distribution of various zooplankton groups in different stations

\begin{tabular}{|c|c|c|c|c|c|c|}
\hline Zooplankton & St:1 & St:2 & St:3 & St:4 & St:5 & St:6 \\
\hline Rotifers & $P$ & $P$ & $P$ & $P$ & $P$ & $P$ \\
\hline Foraminiferans & A & $P$ & $P$ & P & A & $\mathrm{P}$ \\
\hline Tintinnids & $P$ & $P$ & $P$ & $P$ & A & $\mathrm{P}$ \\
\hline Medusae & $P$ & A & A & A & A & A \\
\hline Ephyra larvae & $P$ & A & A & A & A & A \\
\hline Ctenophores & $P$ & A & A & A & A & A \\
\hline Chaetognaths & $P$ & A & A & A & $P$ & A \\
\hline Polychaete larvae & P & P & $\mathrm{P}$ & $\mathrm{P}$ & P & P \\
\hline Trochophore larvae & $P$ & $P$ & $P$ & $P$ & $P$ & A \\
\hline Cladocera & P & A & A & A & $\mathrm{P}$ & $\mathrm{P}$ \\
\hline Ostracods & A & A & A & A & A & A \\
\hline Copepods & $P$ & $P$ & $\mathrm{P}$ & $\mathrm{P}$ & $P$ & $\mathrm{P}$ \\
\hline Balanus nauplii & P & P & $\mathrm{P}$ & $\mathrm{P}$ & $\mathrm{P}$ & A \\
\hline Siphonophores & A & $\mathrm{A}$ & A & A & $\mathrm{P}$ & A \\
\hline Lucifer spp. & P & A & A & A & P & A \\
\hline Amphipods & A & $P$ & $P$ & A & A & A \\
\hline Tunicates & $\mathrm{P}$ & A & A & $\mathrm{P}$ & $\mathrm{P}$ & A \\
\hline Decapod larvae & $\mathrm{P}$ & $P$ & $P$ & $P$ & $\mathrm{P}$ & A \\
\hline Crab zoea & $P$ & A & $P$ & A & A & A \\
\hline Bivalve veliger & $\mathrm{P}$ & $\mathrm{P}$ & $\mathrm{P}$ & $P$ & A & $P$ \\
\hline Gastropods & A & $P$ & A & $P$ & $\mathrm{P}$ & $P$ \\
\hline Fish eggs & $P$ & A & A & A & A & A \\
\hline Fish larvae & $P$ & $P$ & $P$ & $P$ & $P$ & $P$ \\
\hline
\end{tabular}

P-indicates Presence A-indicates Absence

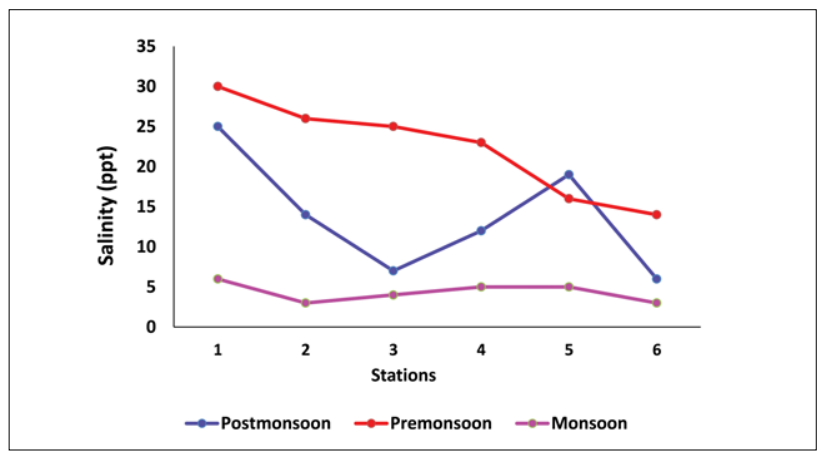

Fig. 4. Seasonwise salinity profile in the study area

Out of the 23 zooplankton groups, 18 were recorded from station 1, 14 from station 3, 13 from station 5, 12 from station $4 \& 2$ and the least of 9 from station 6 (Kottappuram) during the three seasons. From the distribution pattern, it is clear that the salinity plays a major role in the distribution of zooplankton which has also been reported by earlier workers (Nair and Tranter, 1971; Varghese and Krishnan, 2009; Paturej and Gutkowska, 2015; Vineetha et al., 2015). Here also, more diversity and abundance was recorded during the post-monsoon and pre-monsoon months except in stations, 


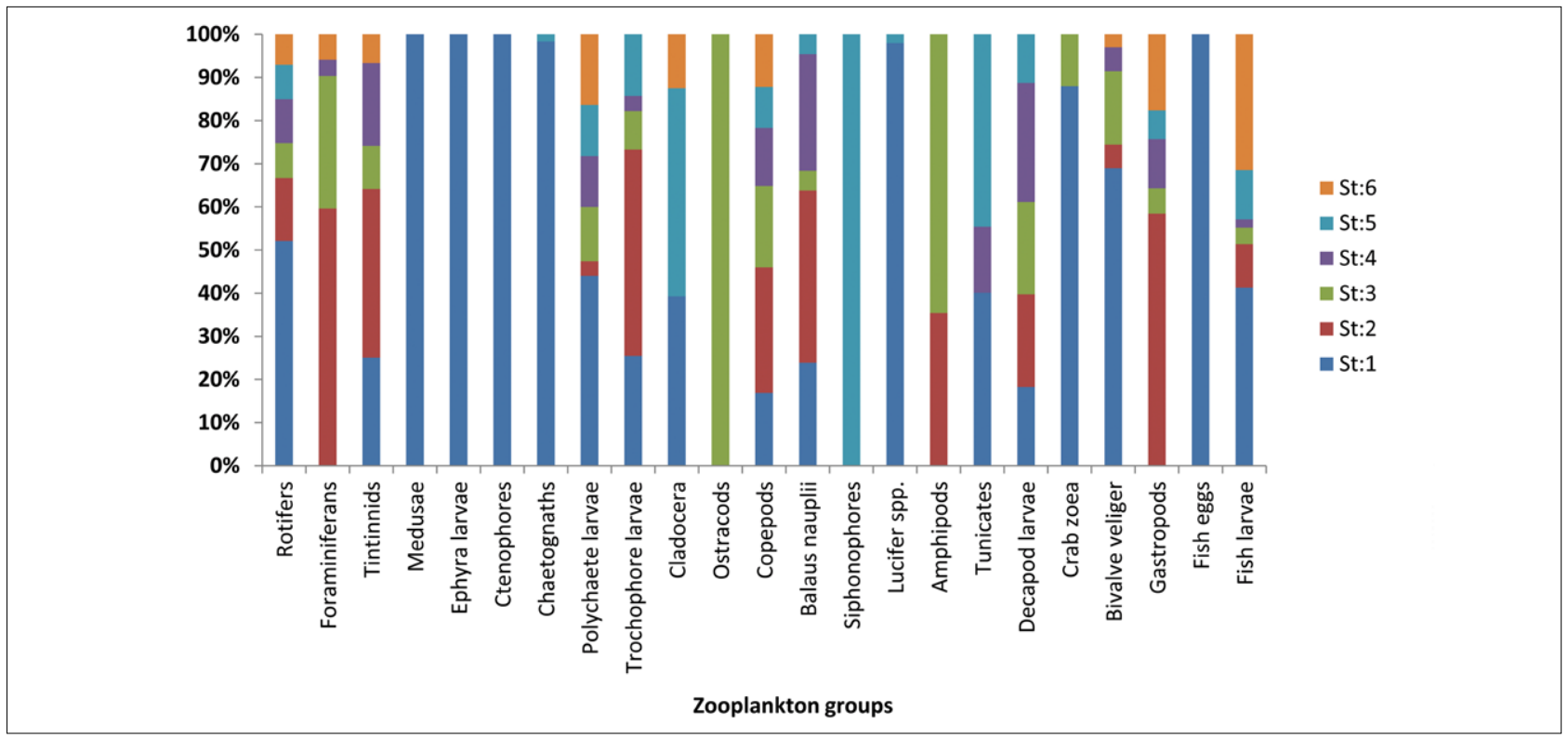

Fig. 5. Community structure of zooplankton in different stations

1 and 2 (Cochin bar mouth and Mulavukad region) where the abundance of zooplankton during the monsoon period is far greater than the other two seasons, when the salinity declined to about an average of $5.5 \& 3 \mathrm{ppt}$ respectively. The situation, however, changed in these two stations during pre and postmonsoons. On comparing these two seasons, pre-monsoon shows a slightly higher salinity range than post-monsoon. Post-monsoon holds the higher density of zooplankton in station $3 \& 6$ whereas station 4 shows hike during pre-monsoon and station 5 shows a similar range during post, pre and monsoon seasons. Earlier studies by Madhupratap and Haridas, 1975; have shown that during monsoon season, only low saline species were able to thrive in the estuary and all the high saline species get wiped off, which is similar to our findings that during monsoon, the abundance of zooplankton at the bar mouth was mainly contributed by low saline copepods. Another fact is that while considering the other four stations, it is clear that the post and pre-monsoon seasons are more favourable for zooplankton. In the former case, being a bar mouth and its near-by area, apart from salinity, other factors like organic matter deposition, active mixing and increased nutrient flux also may be the reason for the zooplankton abundance and diversity.

Among the 23 zooplankton groups, copepods, rotifers, fish larvae and polychaete larvae showed their presence in all the six stations. In this area, $79 \%$ of zooplankton composed of copepods, $14 \%$ rotifers while the remaining groups had contributed only in minor proportions. The dominance of copepods among the zooplankton group in the present study corroborates with the observation of Wellershuas (1974) and Madhu et al. (2007) from Cochin backwaters and Nair and
Table 2. Diversity indices of zooplankton in different months

\begin{tabular}{lllllll}
\hline & $\mathrm{S}$ & $\mathrm{N}$ & $\mathrm{d}$ & $\mathrm{J}^{\prime}$ & $\mathrm{H}^{\prime}$ (loge) & 1-Lambda' \\
\hline Oct-18 & 16 & 112.74 & 3.17 & 0.77 & 2.12 & 0.79 \\
\hline Nov-18 & 10 & 132.39 & 1.84 & 0.63 & 1.45 & 0.60 \\
\hline Dec-18 & 11 & 89.12 & 2.23 & 0.64 & 1.53 & 0.61 \\
\hline Jan-19 & 12 & 42.90 & 2.93 & 0.88 & 2.18 & 0.87 \\
\hline Feb-19 & 10 & 101.04 & 1.95 & 0.69 & 1.59 & 0.68 \\
\hline Mar-19 & 11 & 97.84 & 2.18 & 0.62 & 1.49 & 0.64 \\
\hline Apr-19 & 10 & 95.26 & 1.98 & 0.74 & 1.69 & 0.73 \\
\hline May-19 & 10 & 83.93 & 2.03 & 0.82 & 1.89 & 0.81 \\
\hline Jun-19 & 9 & 111.47 & 1.70 & 0.70 & 1.55 & 0.70 \\
\hline Jul-19 & 8 & 57.37 & 1.73 & 0.66 & 1.38 & 0.66 \\
\hline Aug-19 & 6 & 49.65 & 1.28 & 0.70 & 1.26 & 0.62 \\
\hline Sep-19 & 11 & 182.12 & 1.92 & 0.79 & 1.88 & 0.79 \\
\hline
\end{tabular}

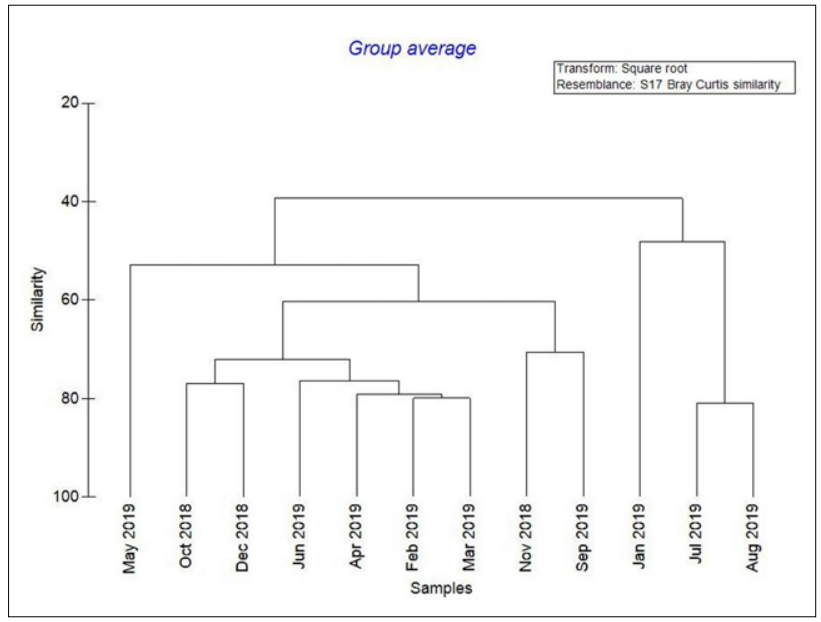

Fig. 6. Hierarchical cluster analysis- month wise 
Table 3. Bray Curtis similarity of different months

\begin{tabular}{|c|c|c|c|c|c|c|c|c|c|c|c|}
\hline Oct-18 & Nov-18 & Dec-18 & Jan-19 & Feb-19 & Mar-19 & Apr-19 & May-19 & Jun-19 & Jul-19 & Aug-19 & Sep-19 \\
\hline \multicolumn{12}{|l|}{ Oct-18 } \\
\hline Nov-18 & 69.6401 & & & & & & & & & & \\
\hline Dec-18 & 76.9718 & 66.8323 & & & & & & & & & \\
\hline Jan-19 & 45.5393 & 36.1279 & 50.7381 & & & & & & & & \\
\hline Feb-19 & 76.3138 & 64.6184 & 79.9121 & 41.7879 & & & & & & & \\
\hline Mar-19 & 68.7254 & 65.9507 & 75.8253 & 40.9715 & 80.006 & & & & & & \\
\hline Apr-19 & 72.9253 & 59.1341 & 67.1879 & 43.501 & 79.098 & 79.18 & & & & & \\
\hline May-19 & 54.4717 & 41.935 & 45.7523 & 42.156 & 60.018 & 57.3267 & 67.2702 & & & & \\
\hline Jun-19 & 67.8917 & 58.3115 & 67.9468 & 37.6761 & 77.153 & 75.5566 & 76.7281 & 59.6486 & & & \\
\hline Jul-19 & 43.6135 & 38.2734 & 33.2092 & 52.4068 & 44.386 & 49.9089 & 47.6379 & 50.4416 & 42.0882 & & \\
\hline Aug-19 & 32.0482 & 27.6288 & 22.0407 & 44.08 & 33.728 & 37.6781 & 36.728 & 35.9018 & 38.9212 & 80.9586 & \\
\hline Sep-19 & 59.5292 & 70.6977 & 56.9358 & 30.0291 & 54.864 & 59.7016 & 55.563 & 37.5044 & 52.868 & 44.3523 & 36.6315 \\
\hline
\end{tabular}

Azis (1987) from Ashtamudy estuary. From the station-wise studies, it is understood that among the six stations four of them showed abundance during post and pre-monsoon. To study and compare the zooplankton diversity during the study period, the data was subjected to diversity analysis. The diversity of zooplankton was assessed using Shannon-Wiener index [H (loge)], Simpson index (1-lambda), Margalef index[d] and Pielou's evenness index [J'] (Table 2).

The Shannon-Weiner's diversity index $\left(\mathrm{H}^{\prime}\right)$ which is the commonly used diversity measure marked the highest $\mathrm{H}^{\prime}$ value of 2.18 in January (post-monsoon) and the lowest value of 1.26 in August (monsoon). The Margalef's richness Index (d) which incorporates the number of individuals (N) and species number $(S)$, showed a higher value 3.17 during October (post-monsoon) and a lower value of 1.28 during August (monsoon). The Pielou's evenness Index (J') which gives the evenness distribution among the different groups gives a value of 0.88 in January (post-monsoon). Simpson Index also marked highest value in January $(0.87)$.Both evenness index and Simpson index marked highest value (0.88 and 0.87 respectively) in January (post-monsoon). The species composition similarity as derived from Bray-Curtis similarity matrix indicated a maximum similarity of $80.95 \%$ between July and August and the most dissimilar months with respect to species distribution was August and December with a similarity percentage of only 22.04 (Table 3 ).

From this Bray-Curtis similarity coefficient, it is inferred that July and August have the maximum similarity in species composition, whereas August and December were the most dissimilar months with respect to species distribution.

A dendrogram (Fig. 6) was constructed which revealed separate grouping based on similarity in species composition and abundance of different months. In the month wise cluster analysis, mainly two clusters were obtained. From the cluster it can be easily understood that the month of July and August shows the maximum similarity of species compared to all the other months.

From the station-wise studies it is inferred that among the six stations, four of them showed abundance of zooplankton during post and pre-monsoon and also copepod dominates among the groups. Temperature and salinity fluctuations are interconnected and result in highly unstable conditions in the estuary that can induce copepod population and seasonal variations in the dominance of the species (Pillai et al., 1973). Different groups of zooplankton were found to flourish according to the suitable conditions of the environments. Usually copepods show an increasing trend with salinity, while rotifers tend to decrease in most cases. In this study, presence of low saline copepod in higher number along with the rotifers, contributed to the increased density of zooplankton during September which had strongly influenced the higher density during the monsoon season in station 2 .

Studies related to the diversity and ecology of zooplankton along the northern part of the Vembanad lake are very scarce. More studies on long term basis have to be conducted, including the hydrographical parameters along this part of the lake possibly help us to derive a reliable conclusion about the distribution and abundance of zooplankton.

\section{Acknowledgements}

The authors are grateful to Dr. A. Gopalakrishnan, Director, ICAR-Central Marine Fisheries Research Institute, Kochi for all the facilities provided for carrying out this work and also to Dr. K. K. Joshi, Head, Marine Biodiversity Division, CMFRI, for 
his encouragements and valuable advice. The first author is also thankful to the CSIR-UGC for the fellowship.

\section{References}

Battish, S. K. 1992. Freshwater zooplankton of India (Chapter IV: Phylum Rotifera). Oxford \& IBH Publishing co. Pvt. Ltd, New Delhi, India, p. 69-114.

Clarke, K. R. and R. N. Gorley. 2006. PRIMER v6: user manual/tutorial, Primer E: Plymouth. Plymouth Marine Laboratory, Plymouth, UK, p. 1-190.

Clarke, K. R. and R. M. Warwick. 2001. Change in marine communities. An approach to statistical analysis and interpretation, 2: 1-168.

Cleetus, R. I., C. V. Asha, P. S. Suson and S. B. Nandan. 2015. Species Diversity and community assemblage of planktonic rotifers from Vembanad Estuary-Kerala, India. Int. J. Oceanogr. Marine Ecol. Sys., 4(1): 1-15.

Gajbhiye, S. N. and B. N. Desai. 1981. Zooplankton variability in polluted and unpolluted waters off Bombay. Mahasagar., 14(3): 173-182.

George, M. J. 1958. Observations on the plankton of the Cochin backwaters. Indian J. Fish., 5(2): 375-401.

Giesecke, R., T. Vallejos, M. Sanchez and K. Teiguiel. 2017. Plankton dynamics and zooplankton carcasses in a mid-latitude estuary and their contributions to the local particulate organic carbon pool. Cont. Shelf. Res., 132: 58-68.

Madhu, N. V., R. Jyothibabu, K. K. Balachandran, U. K. Honey, G. D. Martin, J. G. Vijay, C. A. Shiyas, G. V. M. Gupta and C. T. Achuthankutty. 2007. Monsoonal impact on planktonic standing stock and abundance in a tropical estuary (Cochin backwaters-India). Estuar. Coast. Shelf. Sci., 73(1-2): 54-64.

Madhupratap, M. and P. Haridas, 1975. Composition and variations in the abundance of zooplankton of backwaters from Cochin to Alleppey. Indian J. Mar. Sci., 4: 77-85.
Maya Antony, T. 1991. A study on fluctuation of zooplankton in the estuarine waters at Cochin during May-September 1991 (Doctoral dissertation, Cochin University of Science and Technology).

Nair, K. C. and D. J. Tranter. 1971. Zooplankton distribution along salinity gradient in the Cochin backwater before and after the monsoon. J. Mar. Biol. Ass. India, 13(2): 203-210.

Nair, N. B. and P. K. A. Azis. 1987. Ecology of the Ashtamudi Estuary, southwest coast of India. J. Mar. Biol. Ass. India, 29(1-2): 177-194.

Nandan, S. B. and P. K. A. Azis. 1994. Zooplankton of the retting zones in the Kadinamkulam Estuary, Kerala. Mahasagar., 27(1): 59-65.

Newell, G. E. and R. C. Newell. 1973. Marine plankton- A practical guide. Hutchinson Education Co., Ltd., London. $244 \mathrm{pp}$

Paturej, E. and A. Gutkowska. 2015. The effect of salinity levels on the structure of zooplankton communities. Arch. Biol. Sci., 67(2): 483-492.

Phan, D. D., V. K. Nguyen, T. N. N. Le, N. T. Dang and T. H. Ho. 2015. Identification handbook of freshwater zooplankton of the Mekong River and its tributaries. Mekong River Commission, Vientiane. 207 pp.

Pillai, P. P., S. Z. Qasim and A. K. Nair. 1973. Copepod Component of Zooplankton in a Tropical Estuary. Indian J. Mar. Sci., 2: 38-46.

Qasim, S. Z. 2005. Zooplankton of some major estuaries of India. J. Indian Ocean Stud., 13(3): 439-446.

Srinivasan, A. and R. Santhanam. 1991. Tidal and seasonal variations in zooplankton of Pullavazhi brackishwater, southeast coast of India. Indian J. Mar. Sci., 20(3): 182-186.

Varghese, M. and L. Krishnan. 2009. Distribution of zooplankton in selected centres of Cochin backwaters, Kerala. J. Mar. Biol. Ass. India, 51(2): 194-198.

Vineetha, G., N. V. Madhu, K. K. Kusum and P. M. Sooria. 2015. Seasonal dynamics of the copepod community in a tropical monsoonal estuary and the role of sex ratio in their abundance pattern. Zool. Stud., 54(1): 1-19.

Wellershaus, S. 1974. Seasonal changes in the zooplankton population in the Cochin Backwater (a South Indian estuary). Hydrobiol. Bull., 8(1-2): 213-223. 